\title{
Influence of elongation factor on distributions of effective strain and flow stress for pushing through a conical die process of round bars made from S355 steel
}

\author{
Tomasz Miłek ${ }^{1, *}$ \\ ${ }^{1}$ Kielce University of Technology, Faculty of Mechatronics and Mechanical Engineering, al. Tysiąclecia Państwa Polskiego 7, \\ 25-314 Kielce, Poland
}

\begin{abstract}
The paper presents computer modelling results of researches on pushing through a conical die process of round bars. Calculations were carried out using the commercial code QFORM-2D, based on the Finite Element Method (FEM). Investigations involved the use of circular sectioned S355 (1.0577) steel segments of rods with diameter of $9 \mathrm{~mm}$ and conical dies with different diameter of sizing portion of a die $(\mathrm{d}=$ $7.1 \mathrm{~mm} ; 7.6 \mathrm{~mm}$ and $8.0 \mathrm{~mm}$ ). The aim of the paper is to compare distributions of effective strain and flow stress in longitudinal sections of round bars at different elongation factors $\left(\lambda_{1}=1.24, \lambda_{2}=1.37\right.$ and $\left.\lambda_{3}=1.57\right)$.
\end{abstract}

\section{Introduction}

Drawing, forging with the use of swaging machines and cross rolling are employed while manufacturing stepped parts or reducing the cross section of the shafts and round bars in industrial practice [1-4]. In the 1970s, Marciniak Z. and Kopacz Z. developed a cold rolling method which allowed forming cylindrical gears, involute splines and other circular profiles in Poland [5]. The most essential features of the WPM method, distinguishing it from other known methods, involve the use of two circular segments as tools and adoption of kinematics that allows one-directional rolling with a symmetrical system of forces relative to the axis of the rolled material. In the case when the jaws with internal smooth rolling surfaces are used as tools, it is possible to reduce the cross section of the shafts and tubes. The maximum initial diameter of shaft from medium steel to be reduced is $30 \mathrm{~mm}$ [5]. Relatively new manufacturing technologies of stepped parts are cross-wedge rolling and rolling-extrusion forming process [6]. In the process of rotary forcing, material is formed by means of three rotational tools. The charge is provided by means of a pusher pushing the billet in a working space between the profiled rolls [6].

A place of applying force causing deformation is the main difference between pushing of the material through a die process and drawing process. The force is acting in the entry zone of material in pushing process. Principal stresses depend on yield point (mechanical properties) and degree of deformation of the material $[1,2,7]$. Deformation ratios of the material for drawing process and pushing it through a die process in industrial practice is determined by elongation factor $\lambda$. It is given by formula $[1,3,5,7]$ :

$$
\lambda=\frac{A_{0}}{A_{1}}=\frac{d_{0}^{2}}{d_{1}^{2}}
$$

where:

$$
\begin{aligned}
& A_{0} \text { - cross sectional area of the billet }\left(\mathrm{mm}^{2}\right) \\
& A_{1} \text { - cross sectional area of the material after } \\
& \text { deformation }\left(\mathrm{mm}^{2}\right) \\
& d_{0} \text { - the diameter of the billet }(\mathrm{mm}) \\
& \mathrm{d}_{1} \text { - the diameter of segment of rods after } \\
& \text { deformation }(\mathrm{mm})
\end{aligned}
$$

The paper presents computer modelling results of investigations on pushing through a conical die process of round bars made from S355 steel for different elongation factors. Based on obtained results at relative strains $\varepsilon_{1}=0.35$, the analysis of distributions of effective strain and flow stress in longitudinal sections of steel round bars was conducted. Relative strain was given by formula [6]:

$$
\varepsilon_{l}=\frac{\Delta l}{l_{0}}
$$

where:

$\Delta \mathrm{l}$ - displacement of the punch (mm)

$1_{0}$ - length of the material before deformation $(\mathrm{mm})$ Results of calculations (FEM) of pushing through a conical die process of steel round bars were validated against experimental data in terms of changes in forces for elongation factor $\lambda_{2}=1.37$.

\section{Methodology}

Calculations of metal flow and study distributions of effective strain, flow stress and changes in loading were carried out with commercial code QFORM2D based on Finite Element Method (FEM).

${ }^{*}$ Corresponding author: tmatm@tu.kielce.pl 


\subsection{Model in numerical modelling with QFORM-2D}

The deformed material was incompressible rigid-plastic continuum and elastic deformations were neglected. The system of governing equations included the following [8]:

- equilibrium equations

$$
\sigma_{i j, j}=0
$$

- compatibility conditions

$$
\dot{\varepsilon}_{i j}=\frac{1}{2}\left(v_{i, j}+v_{j, i}\right)
$$

- constitutive equations

$$
\sigma_{i j}^{\prime}=\frac{2 \bar{\sigma}}{3 \dot{\bar{\varepsilon}}} \cdot \dot{\varepsilon}_{i j}
$$

- incompressibility equation

$$
v_{i, i}=0
$$

- expression for flow stress

$$
\bar{\sigma}=\bar{\sigma}(\bar{\varepsilon}, \dot{\bar{\varepsilon}}, T)
$$

where ${ }^{\sigma_{i j} \text { and }} \dot{\varepsilon}_{i j}$ - components of stress and strain-rate tensors, ${ }^{v_{i}}$ - velocity components, ${ }^{\sigma_{i j}^{\prime}}$ - deviatoric stress tensor, $\bar{\sigma}, \bar{\varepsilon}, \dot{\bar{\varepsilon}}-$ effective stress, strain and strain-rate, respectively, $\mathrm{T}$ - temperature.

In Eqs $3 \div 7$, summation convention was used. The prime denoted a derivative with respect to the axis following it. The indexes $i$ and $\mathrm{j}$ for two-dimensional problems varied from 1 to 2 , and repeated subscript represented summation.

The friction model proposed by Levanov et. al [8] was used for the contact region of workpiece surface. Eq. (8) could be considered as a combination of the constant friction model and the Coulomb friction model. The formula combined the advantages of both models [8]:

$$
F_{t}=m \frac{\bar{\sigma}}{3}\left(1-\exp \left(-1,25 \frac{\sigma_{n}}{\bar{\sigma}}\right)\right.
$$

where $\mathrm{m}$ was the friction factor, ${ }^{\sigma_{n}}$ was the normal contact pressure.

\subsection{Boundary conditions in numerical modelling with QFORM-2D}

Chemical composition of material [9] is shown in Table 1.

Table 1. Chemical composition of S355 steel [9].

\begin{tabular}{|c|c|c|c|c|}
\hline $\mathbf{C ~ ( \% )}$ & Mn (\%) & $\mathbf{P ~ ( \% )}$ & $\mathbf{S ~ ( \% ) ~}$ & $\mathbf{S i}(\mathbf{\%})$ \\
\hline 0.23 & 1.60 & 0.05 & 0.05 & 0.05 \\
max. & max. & max. & max. & max. \\
\hline
\end{tabular}

The mechanical properties of the material, determined by static tensile testing, are presented in Table 2. Tensile test was conducted on LabTest5.20SP1 testing machine (LABORTECH firm) with $20 \mathrm{kN}$ force. Machine was calibrated by PN-EN ISO 7500-1:2005 and meets the metrological requirements for class 0.5 (Figure 1).
Table 2 Mechanical properties of specimens made from S355 steel.

\begin{tabular}{|c|c|c|}
\hline $\mathbf{R}_{\mathbf{m}}$ (MPa) & $\mathbf{A}(\mathbf{\%})$ & $\mathbf{A}_{11.3}(\mathbf{\%})$ \\
\hline 737 & 11.2 & 6.5 \\
\hline
\end{tabular}

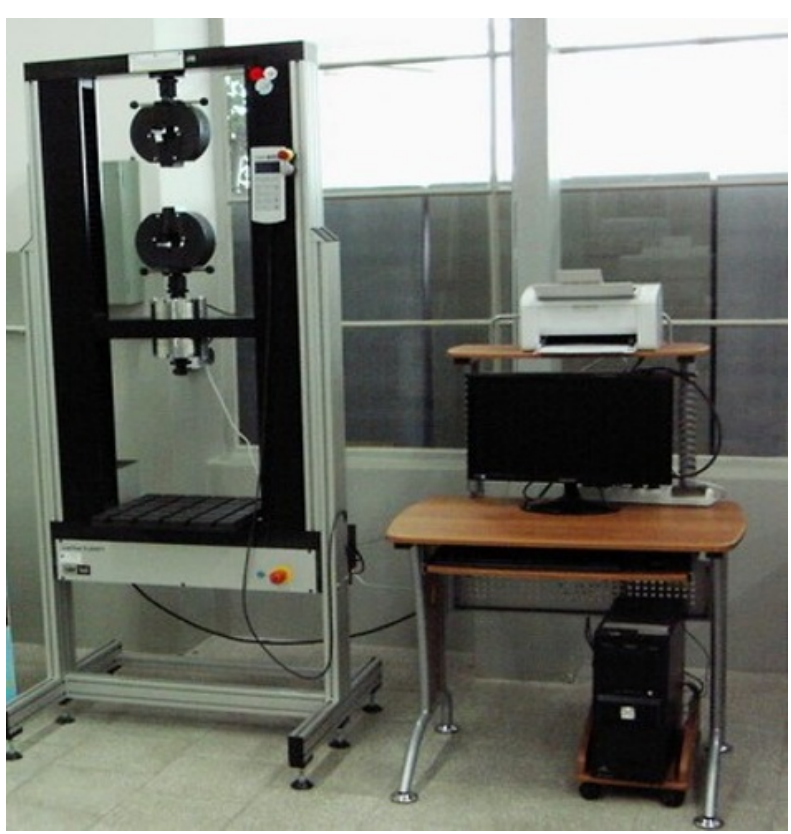

Fig. 1. LabTest5.20SP1 testing machine.

The flow stress characteristics were given as a function of the strain rate. On the basis of investigations (Figure 2), function was adopted for numerical modelling of pushing through a conical die process of round bars made from S355 steel.

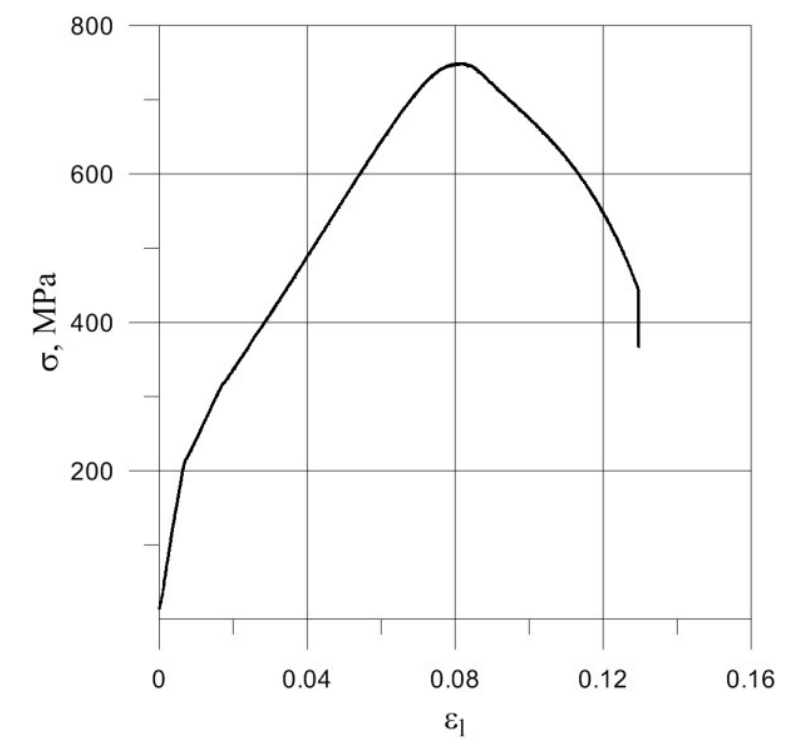

Fig. 2. The flow curve for S355 steel.

Investigations into pushing through a conical die process involved the use of circular sectioned S355 steel segments of rods. Shape and dimensions of specimens are presented in Figure 3. The piece of each rod before 
deformation was reduced by machining to make it easier to enter of the material to sizing portion of a conical dies. Initial workpiece temperatures was $20^{\circ} \mathrm{C}$.

The computer modelling and experimental investigations were conducted for the same friction conditions at a tool/workpiece interface. Mineral oil used in cold deformation of steel at the friction factor $m=0.3$.

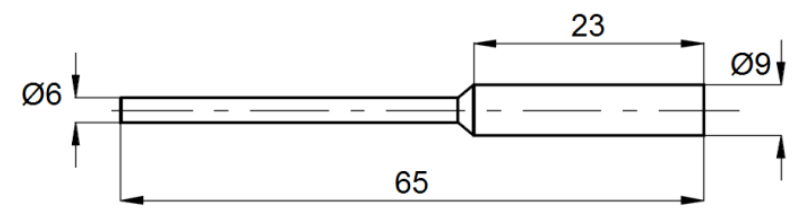

Fig. 3. Shape and dimensions of specimens.

\subsection{Stand for experimental verification of modelling results}

The experimental part of the research was conducted at a special stand which included the following:

- a tool for pushing through a die process of round bars equipped with replaceable conical dies,

- ZD100 testing machine (Figure 4) modified by LABORTECH, $1 \mathrm{MN}$ force (the machine is compliant with metrological requirements for Class 1 and was calibrated as per PN-EN ISO 7500-1:2005),

- a computer stand with Test\&Motion software (LABORTECH) to measure forces and displacements.

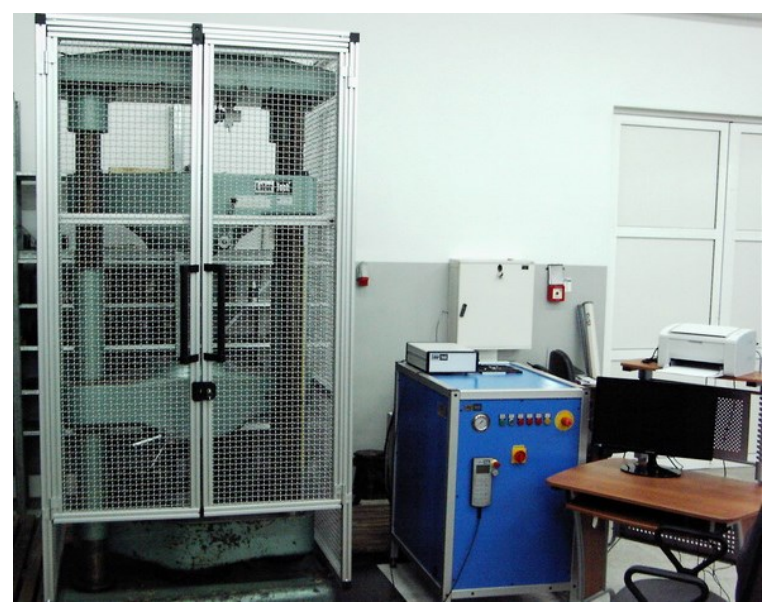

Fig. 4. ZD100 testing machine.

Figure 5 shows the diagram of press tools for pushing through a die process of round bars used in the experiment and computer modelling (FEM). Conical dies with different diameter of sizing portion of a die $(d=7.1 \mathrm{~mm} ; 7.6 \mathrm{~mm}$ and $8.0 \mathrm{~mm})$ and the same cone angle $\left(\alpha=12^{\circ}\right)$ were made from sintered carbides in steel die cases.

The shape and main dimensions of conical dies used in these investigations are presented in Figure 6. The conical shape is very widely used in industry for drawing process since the inner conical shape can be more easily manufactured than other curved inner shapes [1,2]. A cylindrical land with $3 \mathrm{~mm}$ length was used in the drawing dies immediately after the entry cone angle.

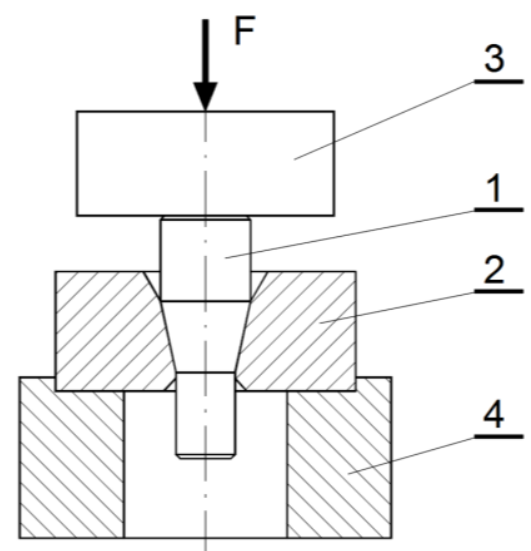

Fig. 5. Tool for pushing through a conical die process, where: 1 - workpiece, 2 - conical die, 3 - punch, 4 - holder of the die.

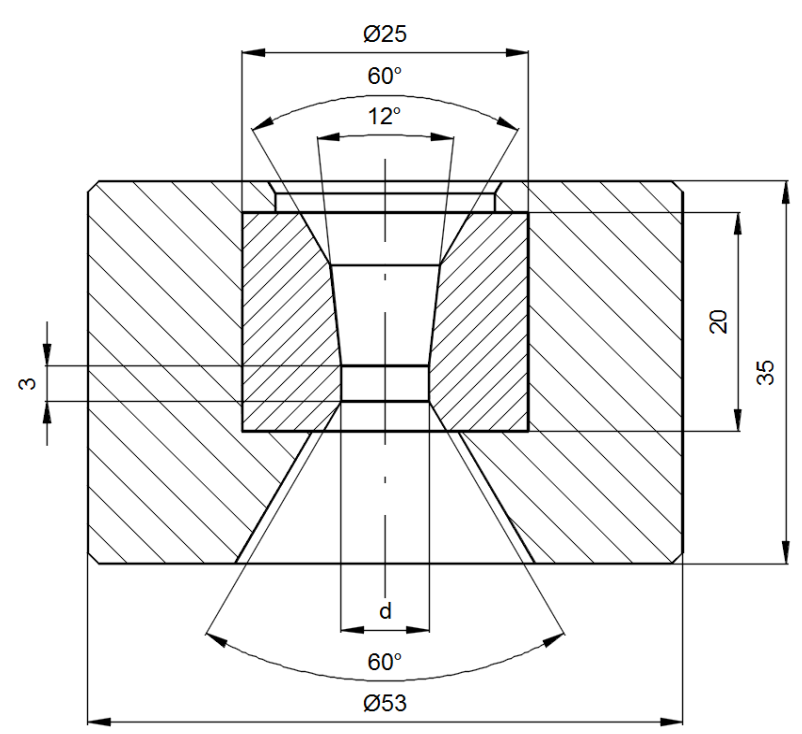

Fig. 6. The shape and main dimensions of conical dies $(\mathrm{d}=7.1 \mathrm{~mm} ; 7.6 \mathrm{~mm}$ and $8.0 \mathrm{~mm})$.

\section{Results and analysis}

The numerical and experimental investigations produced round bars with different nominal diameter: $d_{1}=8 \mathrm{~mm}$, $7.6 \mathrm{~mm}$ and $7.1 \mathrm{~mm}$; which corresponded to different elongation factors: $\lambda_{1}=1.24, \lambda_{2}=1.37, \lambda_{3}=1.57$, respectively. Results of the simulation process showed that the model of boundary conditions, presented in chapters 2.1 and 2.2, proved adequate.

To analyse the displacement and distortion of the metal selected volumes in deformations, the flow lines were imposed. Ten inner flow lines along the $0 \mathrm{X}$ and $0 \mathrm{Y}$ axes were assumed. Numerically calculated last stages of pushing through a conical die process of round bars made from S355 steel for different elongation factors at the same displacement of the punch $\Delta l=8 \mathrm{~mm}$ are presented in Figure 7. 

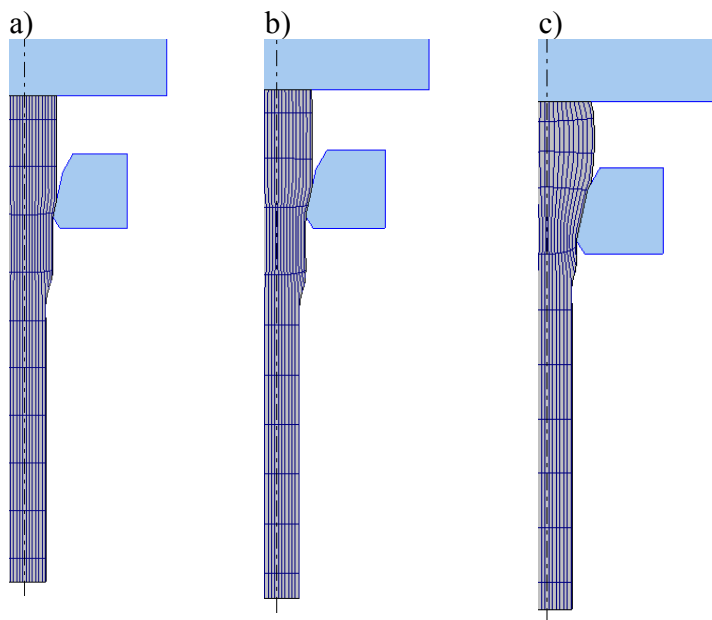

Fig. 7. Numerically calculated last stages of pushing through a conical die process of round bars made from S355 steel for different elongation factors:

a) $\lambda_{1}=1.24$, b) $\lambda_{2}=1.37$, c) $\left.\lambda_{3}=1.57\right)$.

At this displacement it was possible to receive the cylindrical part of initial material without any changes for elongation factors $\lambda_{1}=1.24$ and $\lambda_{2}=1.37$. Pushing through a conical die process of round bars made from S355 steel at $\lambda_{3}=1.57$ elongation factor and displacement of the punch $\Delta l=8 \mathrm{~mm}$ (for relative strain $\left.\varepsilon_{1}=0.35\right)$ caused the upsetting of material under punch and the formation of the so-called "barrel". That was confirmed by the experimental investigations carried out at stand with ZD100 testing machine (Figure 8c). Examples of samples obtained in experimental investigations are presented in Figure 8.

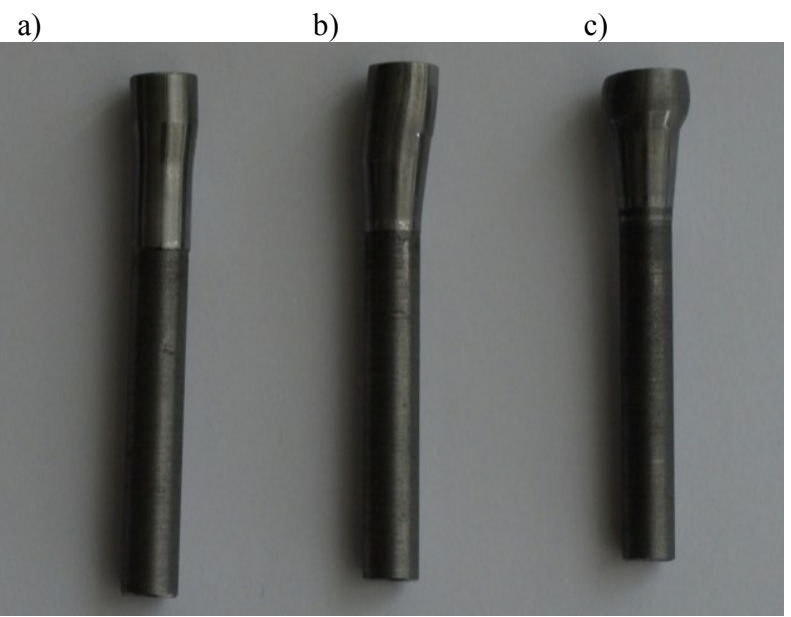

Fig. 8. Examples of experimentally obtained S355 steel samples after pushing through a conical die process for different elongation factors:

a) $\lambda_{1}=1.24$, b) $\lambda_{2}=1.37$, c) $\left.\lambda_{3}=1.57\right)$.

Available literature does not limit pushing through a die process of round bars. In drawing process, which is very similar to its, limits are characterised by the tensile strength of the final cross section. The maximum achievable natural strains $\varphi_{\max }$ are between 0.25 and 0.3 for steels [2]. The natural strain is [2,7]:

$$
\varphi=\ln \left(\frac{A_{0}}{A_{1}}\right)=\ln \left(\frac{d_{0}^{2}}{d_{1}^{2}}\right)
$$

Numerical investigations produced steel round bars with elongation factors: $\lambda_{1}=1.24, \lambda_{2}=1.37, \lambda_{3}=1.57$; which corresponded to different natural strains: $\varphi_{\max }=0.21, \varphi_{\max }=0.31$ and $\varphi_{\max }=0.45$, respectively. The maximum natural strain obtained in simulation $\varphi_{\max }=0.45$ significantly exceeded the maximum possible natural strain in drawing process [2].

Deformation zones (Figure 7) are not bounded by straight lines and circles. They extend from material area near cylindrical land of conical dies (at $\lambda_{1}=1.24$ and $\lambda_{2}=1.37$ ) to small zone in the vicinity of the workpiece axis. In addition, the deformation zone occupies area of the inside barrel of the material between punch and conical die for pushing through a die process of round bar at elongation factor $\lambda_{3}=1.57$ and maximum natural strain $\varphi_{\max }=0.45$. The analysis of the process was conducted based on results of numerically computed effective strain and flow stress distributions at intersections of round bars after pushing through a die process, too (Figure 9 and Figure 10).

The maximum value of the effective strain was found in the last stage of simulation of pushing through a die process of round bars backward at elongation factor $\lambda_{3}=1.57$ and relative strain $\varepsilon_{1}=0.35$ (Figure 9). It reached the value of 0.6113 and it was greater than maximum value of 0.3862 obtained for elongation factor $\lambda_{1}=1.24$ by $58 \%$.

Numerically obtained flow stress distributions are presented in Figure 10.

The highest values of the flow stress were noted in last stages of simulation for different elongation factors. No significant differences were found while analysing these. The highest value of the flow stress was recorded for $\lambda_{3}=1.57$. It amounted to $702.2 \mathrm{MPa}$. The values of flow stress at $\lambda_{1}=1.24$ and $\lambda_{2}=1.37$ were smaller than value obtained for $\lambda_{3}=1.57$. These differences amount to $10 \%$ and $3 \%$, respectively.

Results of calculations of pushing through a conical die process of steel round bars were validated against experimental data in terms of changes in forces for elongation factor $\lambda_{2}=1.37$. In the graphs (Figure 11), $\Delta l$ denotes the displacement of punch.

For the assumed maximum punch displacement $\Delta \mathrm{l}=8 \mathrm{~mm}$ (which corresponded to the relative strain $\left.\varepsilon_{1}=0.35\right)$ successful experimental tests were conducted. The 2D FE models successfully described the pushing through a conical die process of steel round bars. Both in experimental and modelling investigations, the axial force increased together with an increase in the displacement of the punch $\Delta l$ and relative strain $\varepsilon_{l}$. The maximum of experimentally value of force was greater than those obtained numerically calculated (the difference between the maximum values of forces did not exceed $10 \%$ ) at the same maximum relative strain $\varepsilon_{1}=0.35$. 
a)
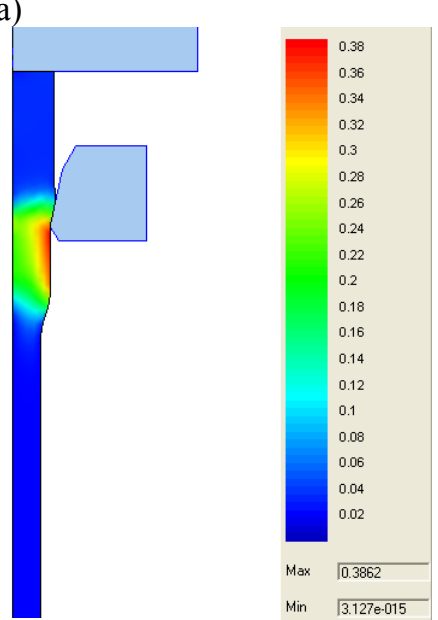

b)

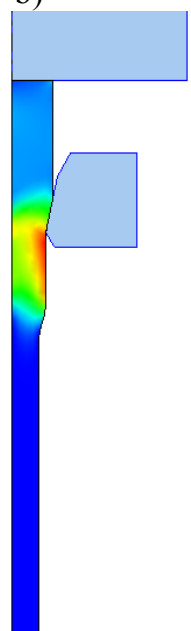

c)
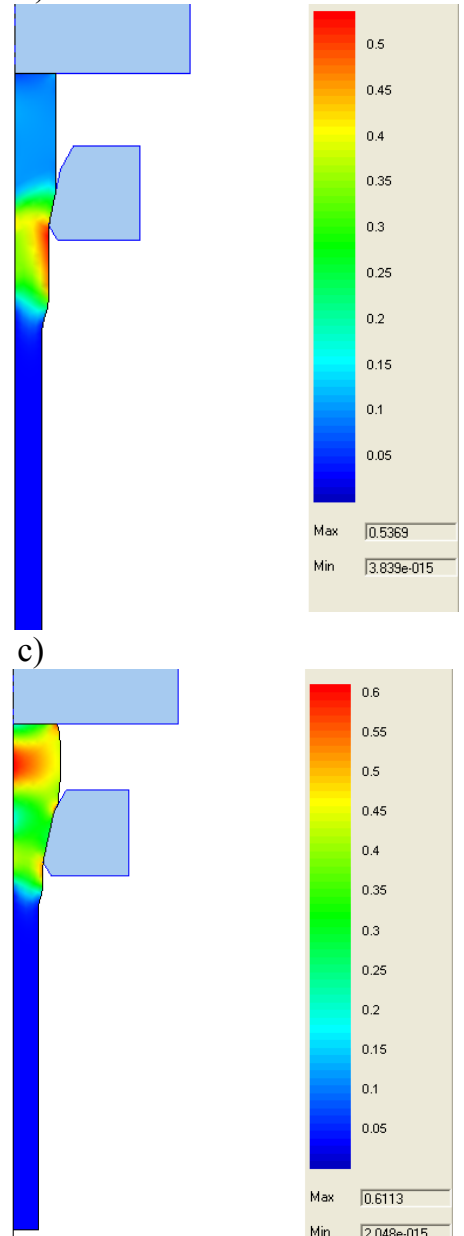

Max $\longdiv { 0 . 5 3 6 9 }$

Min $\longdiv { 3 . 8 3 9 e - 0 1 5 }$

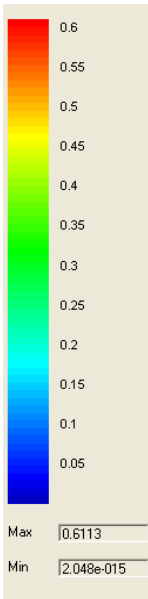

Fig. 9. Numerically computed effective strain distribution at the intersection of round bars made from S355 steel for the last stage of computer modelling of pushing through a conical die process and for different elongation factors: a) $\lambda_{1}=1.24$, b) $\lambda_{2}=1.37$, c) $\lambda_{3}=1.57$. a)

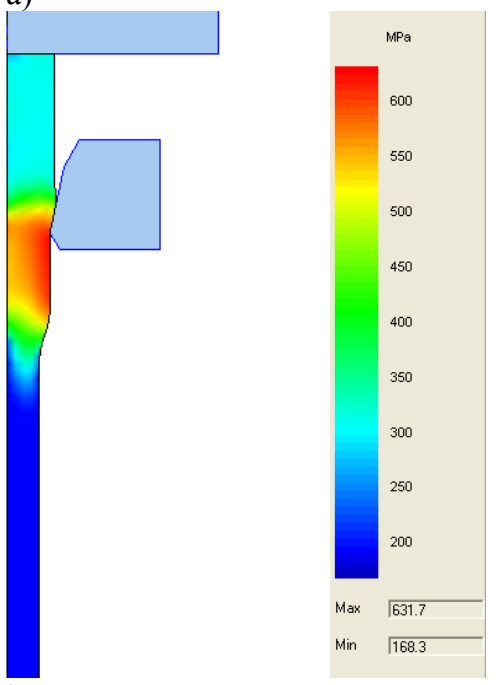

b)
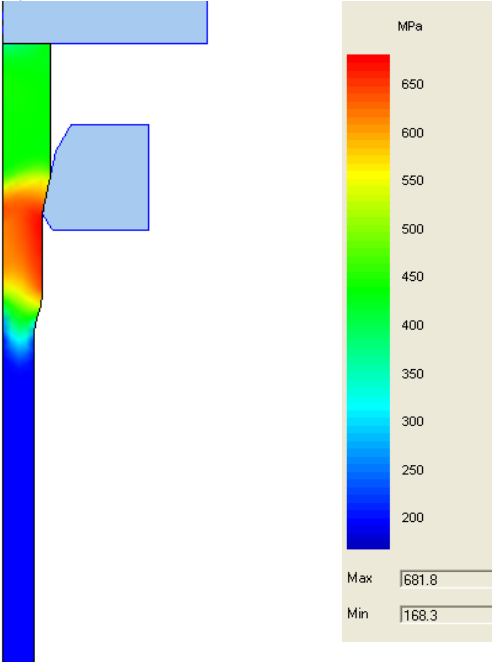

c)
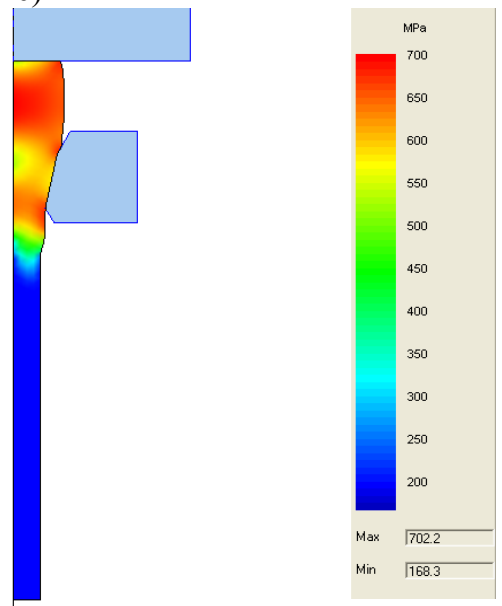

Fig. 10. Numerically computed flow stress at the intersection of round bars made from S355 steel for the last stage of computer modelling of pushing through a conical die process and for different elongation factors: a) $\lambda_{1}=1.24$,

b) $\lambda_{2}=1.37$, c) $\lambda_{3}=1.57$. 


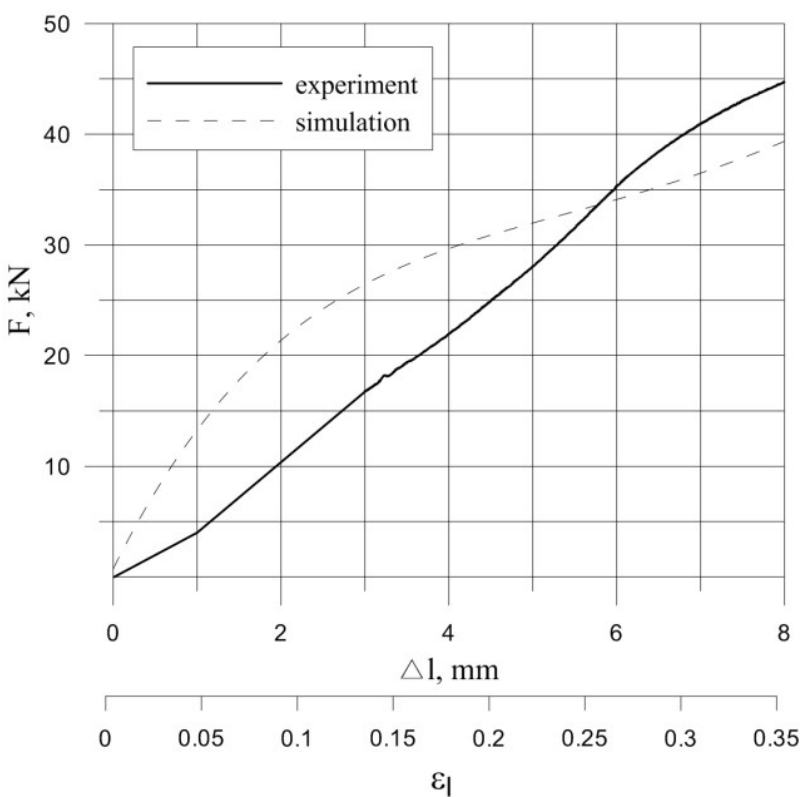

Fig. 11. Comparison between experimental and computer calculated (QFORM-2D) force-travel diagrams of pushing through a conical die process of round bars made from S355 steel for elongation factor $\lambda_{2}=1.37$.

\section{Conclusions}

On the basis of investigations carried out into pushing through a conical die process of round bars made from S355 steel for different elongation factors at cone angle $12^{0}$, it can be stated as follows:

1. Results of the simulation process showed that the $2 \mathrm{D}$ FE model with boundary conditions, presented in article, proved adequate. Results of calculations of pushing through a conical die process of steel round bars were validated against experimental data in terms of changes in forces for elongation factor $\lambda_{2}=1.37$. The 2D FE model successfully described the pushing through a conical die process of steel round bars.

2. It was possible to conduct reducing the cross section of round bars process for elongation factors: $\lambda_{1}=1.24$ and $\lambda_{2}=1.37$ at relative strain $\varepsilon_{1}=0.35$. Pushing through a conical die process of round bars made from S355 steel at assumed maximum value of factor $\left(\lambda_{3}=1.57\right)$ and displacement of the punch $\Delta l=8 \mathrm{~mm}$ caused the upsetting of material under punch and the formation of the so-called "barrel". This phenomenon has been confirmed by experimental investigations. It is affirmed by results of experimental tests presented in previous author's studies [10].

3. The maximum value of the effective strain was found at maximum elongation factor. It was greater than maximum value obtained for minimum elongation factor by approx. $60 \%$.

4. No significant differences were found while analysing the maximum values of flow stress for different elongation factors. The differences between these values did not exceed $10 \%$.

\section{References}

1. M. Schneider, Drawing industry (WGH, Katowice, 1961)

2. K. Lange, Handbook of metal forming (McGrawHill, Inc. USA, 1985)

3. J. Pacanowski, J. Chałupczak, Rudy i Met. Nieżelazne 42, 11, 519 (1997)

4. S. Ziółkiewicz, I. Czartoryska, W. Gronowski, Obróbka Plastyczna Metali 19, 1, 21 (2008)

5. T. Miłek, Z. Kopacz, 24th Int. Conf. on Metallurgy and Materials, 377 (2015)

6. J. Bartnicki, Z. Pater, A. Gontarz, Rudy i Met. Nieżelazne 52/11, 846 (2007)

7. M. Morawiecki, Ł. Sadok, E. Wosiek, Theoretical basis of technological metal forming processes. (Śląsk, 1977)

8. N. Biba, S. Stebunov, A. Vlasov, Steel Res. Int. 79, 611 (2008)

9. S355 EN 10025: Standard Structural Steel Plate. (2004)

10. T. Miłek, Metal 2018: 27th International Conference On Metallurgy And Materials (to be published) 